\title{
Temporal and spatial distribution of trace metals in the Rufiji delta mangrove, Tanzania
}

\author{
Andrew Minu • Joyanto Routh • Mårten Dario • \\ Mario Bilosnic • Rikard Kalén • J. Val Klump • \\ John F. Machiwa
}

Received: 20 October 2017 / Accepted: 26 April 2018 / Published online: 9 May 2018

(C) The Author(s) 2018

\begin{abstract}
Spatial and temporal distribution of trace metals and their cycling is a key issue for understanding the ongoing biogeochemical processes in coastal environments. Sediment cores were collected from six different sampling locations from the Rufiji delta mangrove forests in southeastern coastal Tanzania that are perceived to be impacted by urban development and agricultural activities in the catchment, and pollution in upstream sections of the Rufiji River. The chronology and sediment accumulation rates at these sampling sites were derived based on the distribution of ${ }^{210} \mathrm{~Pb}_{\text {excess }}$ method. The trace metals (As, $\mathrm{Cd}, \mathrm{Cr}, \mathrm{Cu}, \mathrm{Ni}, \mathrm{Pb}$, and $\mathrm{Zn})$ were sequentially extracted as per the BCR method and analyzed. The results indicate that the mass accumulation rates range from $0.40 \mathrm{~g} \mathrm{~cm}^{-2}$ year ${ }^{-1}$ (cores NR3 and NR4) to $1.75 \mathrm{~g} \mathrm{~cm}^{-2}$ year $^{-1}$ (core SR1). Trace metals in the cores are mainly associated with the residual phase and their abundances in sediments are ranked as $\mathrm{Cr}>\mathrm{Zn}>\mathrm{Ni}>\mathrm{Cu}>\mathrm{Pb}>\mathrm{Cd}$. The results imply that trace metals in the Rufiji delta mangroves are mainly of crustal origin, and they are less sensitive to weathering.
\end{abstract}

A. Minu · J. F. Machiwa

Department of Aquatic Sciences and Fisheries, University of

Dar es Salaam, Box 35064, Dar es Salaam, Tanzania

J. Routh $(\varangle) \cdot$ M. Dario $\cdot$ M. Bilosnic $\cdot$ R. Kalén

Department of Thematic Studies-Environmental Change,

Linköping University, SE-58183 Linköping, Sweden

e-mail: joyanto.routh@liu.se

J. Val Klump

School of Freshwater Sciences, Great Lakes WATER Institute, 600

E. Greenfield Ave., Milwaukee, WI 53204, USA
Further, these metals are least available for uptake by plants and they pose limited threat to the biota.

Keywords Trace metals · Sequential extraction . Sediments · Geoaccumulation · Enrichment factor

\section{Introduction}

Mangrove forests located in the inter-tidal zones of tropical and sub-tropical regions are both ecologically as well as economically important coastal ecosystems. The indirect and the most important value of mangroves lie in their protective role (Marchand et al. 2012; Ranjan et al. 2013). Mangrove forests help in protecting the coastlines by preventing erosion and loss of land cover by depositing large quantities of silt. The trees with their mat-like pneumatophore roots have high binding capacity for fine-grained clay and silt-rich sediments. Notably, mangrove sediments are characterized by their high organic matter (OM) content, poor nutrient quality, high amount of sulfide, and low oxygen levels (Ranjan et al. 2013). This makes mangrove sediments a sink (Aderinola et al. 2009), or for that matter even a source for various metalbound particles that actively participate in the ongoing biogeochemical reactions (Marchand et al. 2012). Metal concentrations in these sediments depend on sediment particle size and stability of sulfide-rich minerals under anoxic conditions. Moreover, depending on the pore water conditions (Eh-pH, temperature, and salinity), these metals can transform their oxidation state, and concentrate in plant tissues resulting in long-term 
damaging effects (Marchand et al. 2012). Mangroves acting as a sink for metals may thus pose a threat in future through the release of these metals into the environment on decomposition of mangrove vegetation and/ change in physicochemical conditions. Hence, there is a chance of these mangroves could become a secondary source of various metal pollutants. However, trace metals mostly accumulate in surface sediments temporarily, and they are remobilized and/or re-suspended into the water column under varying environmental conditions. Destruction of mangrove forests can therefore promote remobilization of metals trapped in sediments and facilitate their transport to adjacent areas. These studies on biogeochemical processes have resulted in a keen interest about metal cycling in mangrove ecosystems (Mremi and Machiwa 2003; Marchand et al. 2012; Rumisha et al. 2012; Mrutu et al. 2013; Ranjan et al. 2013).

Tanzania accounts for ca. $0.90 \%$ of the mangrove vegetation cover worldwide. They are spread over an area of about $1155 \mathrm{~km}^{2}$ in a N-S transect along the Indian Ocean coast. In the past, there have been some investigations on mangroves in the Rufiji delta in Tanzania. For example, Paul and Oliver (2005) reported the case of substantial mortality in mangrove trees in the delta following severe and prolonged El-Nino events. Tafe (1990) compared the distribution of zooplankton in terms of different salinity gradients in mangrove stands. However, very little is known about distribution of trace metals or its cycling in the Rufiji delta. Largely, natural processes (weathering and erosion) and human activities (urbanization, discharge from upstream sections, and agriculture) in the catchment drive these changes. Hence, the primary objectives of the present study are to assess the distribution and mobility of trace metals in the Rufiji delta mangroves using the BCR sequential extraction protocol of the Standards, Measurement and Testing Program (formerly the Community Bureau of Reference of the European Commission) to trace the accumulation of metals sorbed to different sediment fractions. Secondly, we want to establish if accumulation of trace metals (e.g., $\mathrm{Cd}, \mathrm{Cr}, \mathrm{Cu}, \mathrm{Pb}$, and $\mathrm{Ni}$ ) in the Rufiji sediments poses a threat to the flora due to their accumulation in the readily exchangeable sediment fraction. Hence, our focus is on the upper $200 \mathrm{~cm}$ in these cores retrieved from mangrove sites (dating back to the early 1800s) to trace the anthropogenic changes in the Rufiji delta, and its effects on the environment. To the best of our knowledge, the study provides the first broad overview about trace metal distribution in the Rufiji delta, which will be helpful for management practices to control pollution and/or launching suitable remediation practices.

\section{Materials and methods}

\section{Study area}

The study area is in the Rufiji delta, $100 \mathrm{~km}$ south of Dar es Salaam. The Rufiji River has a catchment spread over $177,400 \mathrm{~km}^{2}$ and is over $640 \mathrm{~km}$ long (UNEP 2001). Nearly $30 \mathrm{~km}$ from the coast, the lower stretches of the Rufiji River forms a series of channels leading into a delta. A large section of the delta is covered by mangrove forests extending from $39^{\circ} 07^{\prime} \mathrm{E}, 7^{\circ} 41^{\prime} \mathrm{S}$ to $39^{\circ} 45^{\prime} \mathrm{E}, 8^{\circ} 15^{\prime} \mathrm{S}$, which in fact forms the largest stretch of mangrove forests on the east African coast (Kilimwiko 1997). It is linked to the interior river system by an extensive flood plain. The mangrove stand covers an area of $480 \mathrm{~km}^{2}$, which is about $42 \%$ of the total area covered by mangrove forests in Tanzania (Fig. 1). Four tributaries discharge freshwater into the northern part of the delta. The southern part of the delta receives less freshwater and is more saline and affected by tides. Eight mangrove species occur in the Rufiji delta forests, of which, Rhizophora mucronata, Avicennia marina, and Heritiera littoralis are the dominant species. Other species include Bruguiera gymnorrhiza, Ceriops tagal, Lumnitzera racemosa, Sonneratia alba, and Xylocarpus granatum (Semesi 2002). Soil type in the Rufiji delta is mostly black loamy soil and rice is cultivated widely. Large sections in upstream areas and within the delta have been cleared for rice cultivation (Taylor et al. 2003). Pesticides and fertilizers are widely used to increase agriculture output (Taylor et al. 2003). In addition, the upstream section in Rufiji River has many small towns and local industries with poor sanitation facilities that possibly contribute to the pollution in this relatively pristine area. Lax environmental regulations and poor enforcement of existing laws (Byers et al. 2012) further complicate the situation.

\section{Sampling}

We selected six sampling stations in mangrove forests based on the dominant vegetation cover, tidal hydrodynamics, and closeness to areas with potential 


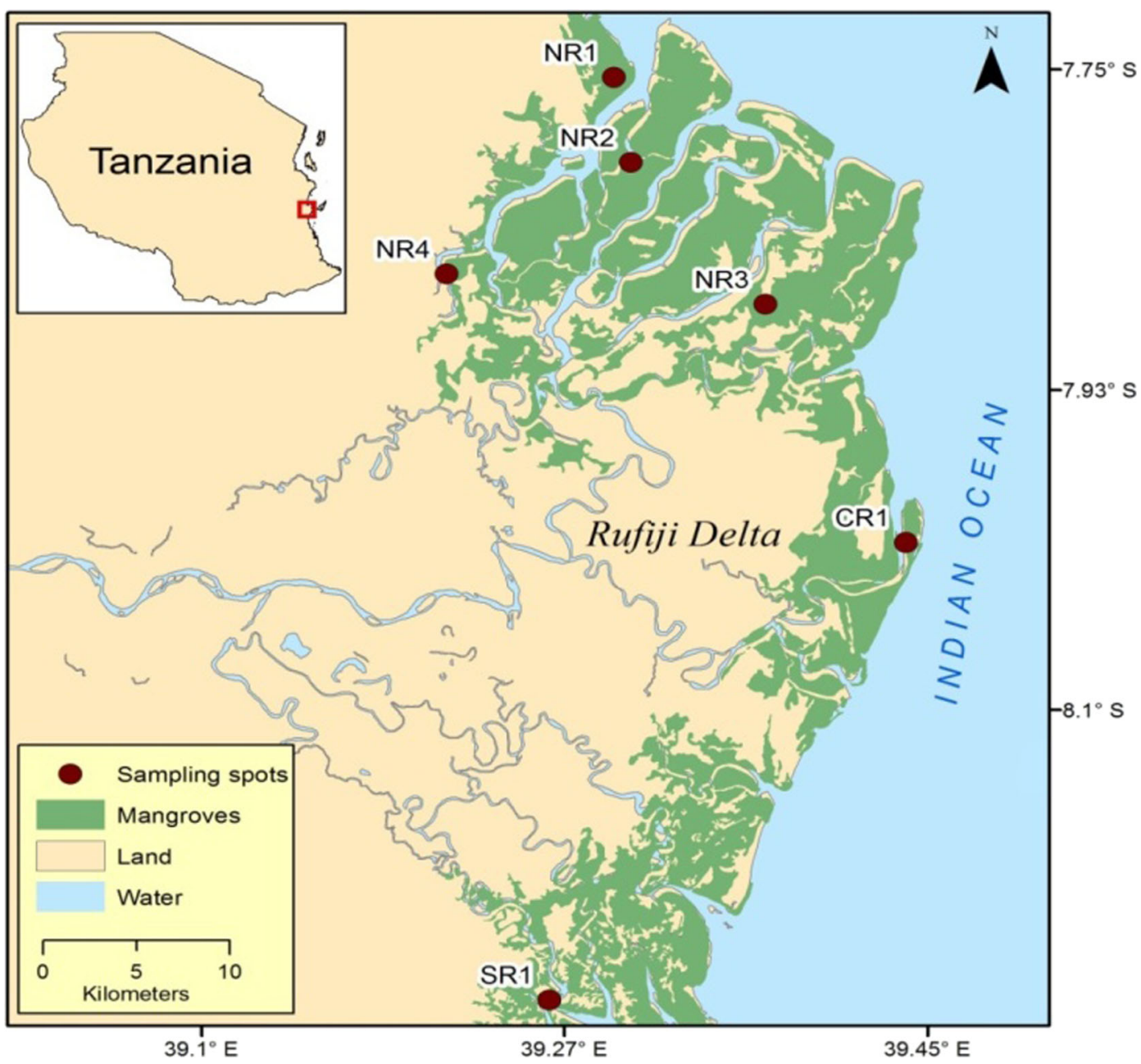

Fig. 1 The Rufiji mangrove delta in Tanzania showing the sampling stations (modified from Google map)

anthropogenic waste discharge outlets (Fig. 1). The sampling site in the northern part of the delta included station NR1 (R. mucronata dominated), station NR2 (A. marina and A. alba dominated), and station NR3 (A. marina dominated). The NR3 site differed from the other sampling stations because it is a semi-desert. The area consists of dry flat land with small prop roots sticking out in air from the soil zone. The core retrieved from NR3 was black and had strong odor of hydrogen sulfide. Station NR4 (H. littoralis dominated) had very hard sticky clay and fine-sand. In central part of the mangrove forest, we had one sampling station (CR1) that had $R$. mucronata as the dominant vegetation cover. Large prop roots occur all around this area and Sonneratia trees have been selectively logged in the forest because of its high value. The southern sampling station (SR1) is dominated by $S$. alba and A. marina species. This area gets inundated during high tides and remains partly submerged.

A Russian peat corer was used to retrieve the sediment cores by pushing the corer through the sediment column and transferring them to longitudinally sliced PVC pipes $(50 \mathrm{~cm}$ long and $5 \mathrm{~cm}$ diameter). The core slices were wrapped in aluminum foil and plastic sheet and transported to the laboratory in cooler boxes. Intact sediment cores were obtained at $50 \mathrm{~cm}$ intervals, and the total core lengths at these six sites ranged from 200 to $650 \mathrm{~cm}$ in length. The sediment cores were sliced at $1 \mathrm{~cm}$ interval for the first $20 \mathrm{~cm}$ in each core and thereafter, the rest of the core was sliced at $2 \mathrm{~cm}$ interval with a stainless-steel saw. The outside edges of each slice are removed using a titanium knife to avoid any possible contamination (Givelet et al. 2004). The sediments were 
freeze-dried and used for various geochemical analyses that are described below.

\section{Reagents}

All reagents were of analytical reagent grade unless otherwise stated. Double deionized water (Milli-Q water) was used for all dilutions. All standards, reagent solutions, and samples were kept in polyethylene containers. Acetic acid (glacial, 100\% Fisher Scientific, UK), hydroxylammonium chloride (99\% ACROS Organics, USA), hydrogen peroxide (30\% Fisher Scientific, UK), and ammonium acetate (99.99\%) and $\mathrm{HNO}_{3}$ (65\%) (from Suprapur Merck, Germany) were of super pure quality. The plastic and glassware were cleaned by soaking in dilute $\mathrm{HNO}_{3}$ and were rinsed with deionized water prior to use. Standard metal solutions (1000 mg/L) were purchased from Merck (Darmstadt, Germany) or prepared in the laboratory from pure metals. The extractants were prepared as reported in Nemati et al. (2011).

Texture and organic matter content in Rufiji sediments

About $6 \mathrm{~g}$ of freeze-dried sediment samples were first passed through a $63-\mu \mathrm{m}$ sieve (US EPA 2010). The sand (>63 $\mu \mathrm{m}$ size) content was determined gravimetrically. The fine fraction $(<63 \mu \mathrm{m})$ remaining was homogenized in $80 \mathrm{~mL}$ of $0.05 \%$ sodium hexametaphosphate (Centeri et al. 2015) with an ultrasonic stirrer for $3 \mathrm{~min}$. Grain size distribution in the $<63 \mu \mathrm{m}$ sediment suspension was determined with a Micromeritics SediGraph III for the amount (\%) of silt and clay content. For estimating the organic matter in samples, about $0.2-0.5 \mathrm{~g}$ of freeze-dried samples were heated at $105^{\circ} \mathrm{C}$ in an oven for $12 \mathrm{~h}$. After cooling, the samples were stored inside a desiccator and weighed again, the samples were heated in a furnace at $550{ }^{\circ} \mathrm{C}$ for $4 \mathrm{~h}$. The organic matter content was calculated as the total weight lost by the sample on heating (Heiri et al. 2001).

${ }^{210} \mathrm{~Pb}$ chronology

We applied the constant initial concentration (CIC model) to trace the down-core excess ${ }^{210} \mathrm{~Pb}\left({ }^{210} \mathrm{~Pb}\right.$ ex $)$ profile. The CIC model assumes constant initial concentration of ${ }^{210} \mathrm{~Pb}_{\mathrm{ex}}$ in surface sediments that is independent of the sedimentation rate (Krishnaswamy et al. 1971). With this model, the sedimentation rate can be calculated using the slope derived from linear regression of $\ln$ ${ }^{210} \mathrm{~Pb}_{\mathrm{ex}}$ and the depth (x) according to Eq. 1 (Appleby and Oldfield 1983)

$\mathrm{C}=\mathrm{C}_{\mathrm{o}} \mathrm{e}^{-\mathrm{kr}}$

where $\mathrm{C}_{\mathrm{o}}$ is the ${ }^{210} \mathrm{~Pb}_{\mathrm{ex}}$ concentration $\left(\mathrm{Bq} \mathrm{kg}{ }^{-1} \mathrm{~d} \mathrm{~m}\right)$ in surface sediment, $\mathrm{k}$ is the radioactive decay constant $\left(0.03114\right.$ year $\left.^{-1}\right)$, and $r$ is the sedimentation rate. The age ( $\mathrm{t}$ ) of a sediment layer with ${ }^{210} \mathrm{~Pb}$ concentration $\mathrm{C}$ $\left(\mathrm{Bq} \mathrm{kg}{ }^{-1} \mathrm{~d} . \mathrm{m}\right)$ is determined based on Eq. 2

$\mathrm{t}=\frac{1}{\mathrm{k}} \ln \frac{\mathrm{C}(\mathrm{o})}{\mathrm{C}}$

The sediment age was estimated based on the slope of the line to calculate the sedimentation rate $\left(\mathrm{cm}\right.$ year $\left.^{-1}\right)$. To account for compaction in the layers, linear regression of the natural logarithm of ${ }^{210} \mathrm{~Pb}_{\mathrm{ex}}$ $(\mathrm{dpm} / \mathrm{g})$ in dry sediments vs. the cumulative dry mass ( $\mathrm{g} \mathrm{cm}^{-2}$; Fig. 2) was calculated from bulk density of the sediment layer versus depth. This was used to estimate the sediment accumulation rate, (w) as gram per square centimeter per year.

The sediments were dated at the University of Wisconsin-Milwaukee by the ${ }^{210} \mathrm{~Pb}$ method. Prior to analysis, all samples were stored in sealed containers in the laboratory for more than 1 year. The ${ }^{210} \mathrm{~Pb}$ geochronology analytical procedure takes advantage of the fact that, within 2 years, secular equilibrium is achieved between ${ }^{210} \mathrm{~Pb}$ and its granddaughter ${ }^{210} \mathrm{Po}$ in sediments, so that both isotopes have the same activity level. After drying and homogenization, the ${ }^{210} \mathrm{~Pb}$ activity was determined the chronology (Fuller et al. 1999; Krishnaswamy et al. 1971). In short, the procedure involved addition of ${ }^{209} \mathrm{Po}$ as a tracer to the sediments to determine the chemical recovery and plating efficiency. The dried sediment (ca. $1 \mathrm{~g}$ ) was then digested in $6 \mathrm{~N}$ $\mathrm{HCl}$ acid for $30 \mathrm{~min}$ at $95{ }^{\circ} \mathrm{C}$, allowed to cool briefly, and four sequential $1 \mathrm{~mL}$ aliquots of $30 \%$ hydrogen peroxide and 1 drop of octanol were added at an interval of $30 \mathrm{~min}$ to oxidize the organic matter. Samples were then digested for $4 \mathrm{~h}$ in $6 \mathrm{~N} \mathrm{HCl}$ and allowed to cool overnight. The samples were filtered to remove sediment and the solution reduced in volume by heating. Sample volume was then brought up to $50 \mathrm{~mL}$ with Epure water; the $\mathrm{pH}$ was adjusted up to 1.0 by adding 100-200 mg of ascorbic acid and the solution was transferred to a plastic bottle. Polonium was plated onto one side of a copper disk at $95^{\circ} \mathrm{C}$ in an oven. The plates 

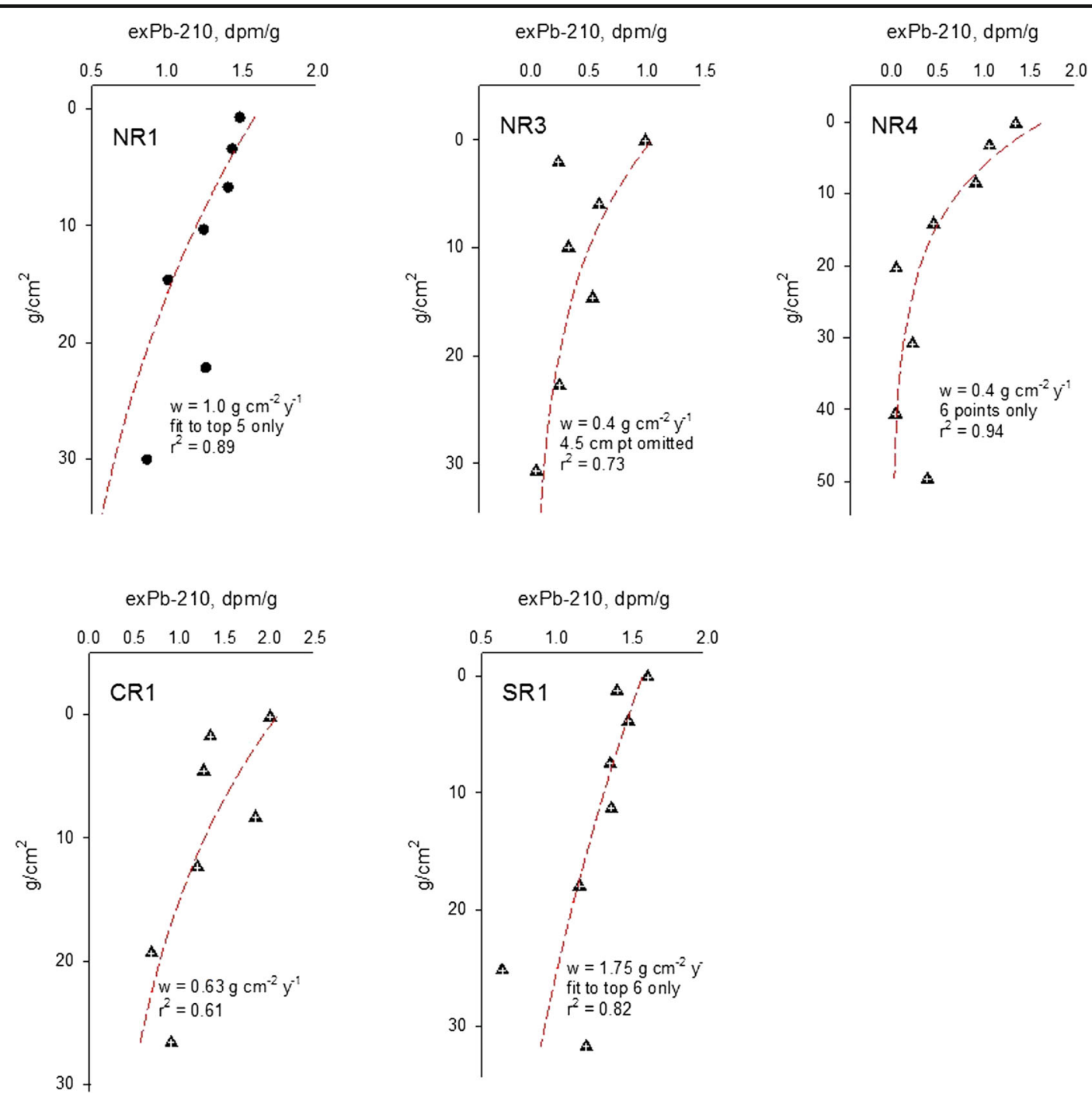

Fig. $2{ }^{210} \mathrm{~Pb}$-based geochronology in the Rufiji delta sediment cores

were counted for $60,000 \mathrm{~s}$ on an Ortec dual-alpha spectrometer interfaced with a multi-channel analyzer. The samples were dated up to a depth of $30 \mathrm{~cm}$ in the core.

\section{Metal analyses}

Metal analysis in mangrove sediments is based on the $\mathrm{BCR}$ sequential extraction method to determine trace metals concentrations in different geochemical fractions (e.g., carbonate, sulfidic, organic, oxide, or residual phases). Minor modification was made to the existing protocol and $7 \mathrm{M} \mathrm{HNO}_{3}$ was used instead of aqua-regia for extraction of trace metals in the residual fraction and for pseudo-total extraction (Borgese et al. 2013; SIS 2003). Certified reference sediments (CRM-601) and duplicate samples were used to test the accuracy and efficiency of the extraction procedure, and reproducibility of our results. Two blanks (procedural blank and step blank) were analyzed with each set of 10 samples to evaluate the results.

An internal check was performed on the results of the sequential extraction method by comparing the total amount of metals extracted by different reagents during the sequential extraction procedure with results of the pseudo-total digestion. The recovery of the sequential extraction method was calculated using Eq. 3 as reported in Nemati et al. (2011):

$$
\% \text { Recovery }=\frac{\sum(\mathrm{F} 1+\mathrm{F} 2+\mathrm{F} 3+\mathrm{F} 4)}{\mathrm{T}_{\mathrm{p}}} \times 100
$$


where F1, F2, F3, and F4 were the different fractions and $T_{p}$ was the pseudo-total metal concentration as per the BCR extraction scheme. Analytical results obtained for the reference materials differed by $<10 \%$ from certified values (Table 1)

Exchangeable (water and acid soluble) fraction (F1) About $0.5 \mathrm{~g}$ of accurately weighed sediment sample was extracted with $20 \mathrm{~mL}$ of $0.11 \mathrm{M}$ acetic acid and shaking it for $16 \mathrm{~h}$ that was followed by centrifuging the sample at $3000 \mathrm{~g}$ for $20 \mathrm{~min}$ at $20^{\circ} \mathrm{C}$. After centrifugation, the supernatant was carefully decanted and stored for further analyses. The residue was washed with $60 \mathrm{~mL}$ of distilled water by shaking for $15 \mathrm{~min}$, centrifuged, and the washings discarded.

Reducible (iron/manganese oxide) fraction (F2) The residue from $\mathrm{F} 1$ fraction left was extracted with $20 \mathrm{~mL}$ of $0.11 \mathrm{M}$ hydroxylamine hydrochloride ( $\mathrm{pH} 2.0$ ), and after shaking it for $16 \mathrm{~h}$, the extract was filtered. The samples were centrifuged for $20 \mathrm{~min}$ at $3000 \times \mathrm{g}$ and $20{ }^{\circ} \mathrm{C}$. After centrifugation, the supernatant was carefully decanted and stored for analyses. The residue was washed with $60 \mathrm{~mL}$ of distilled water by shaking for $15 \mathrm{~min}$, centrifuged, and the washings discarded.

Oxidizable (organic and sulfide) bound fraction (F3) To the residue from $\mathrm{F} 2$ fraction, $5 \mathrm{~mL}$ of $8.8 \mathrm{M} \mathrm{H}_{2} \mathrm{O}_{2}$ was added in small aliquots and left for $1 \mathrm{~h}$ at room temperature to react. Another $5 \mathrm{~mL}$ of $\mathrm{H}_{2} \mathrm{O}_{2}$ was added and heated at $85{ }^{\circ} \mathrm{C}$ in a water bath. Afterwards $25 \mathrm{~mL}$ of $1 \mathrm{M}$ ammonium acetate ( $\mathrm{pH}$ 2.0) was added to the reaction mixture, and it was extracted after $16 \mathrm{~h}$ of shaking. The samples were centrifuged for $20 \mathrm{~min}$ at $3000 \mathrm{~g}$ and $20^{\circ} \mathrm{C}$. After centrifugation, the supernatant was carefully decanted and stored for further analyses. The residue was washed with $60 \mathrm{~mL}$ of distilled water by shaking for $15 \mathrm{~min}$, centrifuged, and the washings discarded.

Residual bound fraction (F4) To the residue from F3 fraction, $10 \mathrm{~mL}$ of $7 \mathrm{M} \mathrm{HNO}_{3}$ was added, and the reaction mixture was placed in an autoclave at $121{ }^{\circ} \mathrm{C}$ and $200 \mathrm{kPa}$ for $30 \mathrm{~min}$. After cooling, the samples were centrifuged for $20 \mathrm{~min}$ at $3000 \mathrm{~g}$ and $20{ }^{\circ} \mathrm{C}$. The supernatant was carefully decanted and stored for further analyses and the remaining sediments were discarded.
Pseudo-total dissolution Of sediment, $0.5 \mathrm{~g}$ was weighed and $10 \mathrm{~mL}$ of $7 \mathrm{M} \mathrm{HNO}_{3}$ was added and the reaction mixture was autoclaved at $121^{\circ} \mathrm{C}$ and $200 \mathrm{kPa}$ for $30 \mathrm{~min}$ (SIS 1993). After cooling, the samples were centrifuged for $20 \mathrm{~min}$ at $3000 \mathrm{~g}$ and $20{ }^{\circ} \mathrm{C}$. After centrifugation, the supernatant was decanted carefully and stored in a $50-\mathrm{mL}$ acid washed tube; the remaining sediment was discarded.

The mineral fractions obtained during each extraction step (fractions 1 through 4) and pseudo-total metal concentrations were analyzed on an ICP-MS (Perkin Elmer NexION 350). Prior to analysis, an internal standard was added, and the samples were diluted with deionized water. To evaluate the reliability of the extraction procedure, the reference standard CRM-601 was extracted, and analyzed for six certified trace metal concentrations in similar manner as the sediment samples.

Trace metal enrichment in sediments

Anthropogenic input of trace metals in the Rufiji delta sediments was assessed by estimating the metal enrichment factor with respect to its background concentration. In absence of data on metal concentrations from pristine areas, the average continental crust (Rudnick and Gao 2003) or continental crustal abundances (Taylor and McLennan 1995) were used as background values of metals to calculate enrichment factors. Two approaches were used for comparing the metal enrichment factor at these sites in the Rufiji delta.

$I_{\text {geo }}$ in this study was calculated using the geoaccumulation index proposed by Muller (1969). This index (Igeo) of trace metal is calculated by computing the base 2 logarithm of the measured total concentration of the metal over its background concentration (Abrahim and Parker 2008)

$\mathrm{I}_{\text {geo }}=\log _{2}\left(\frac{\mathrm{C}_{\mathrm{x}}}{1.5 \mathrm{~B}_{\mathrm{x}}}\right)$

where $C_{x}$ was the concentration of analyte " $x$ " in sediment, $B_{x}$ was the geochemical background concentration of analyte " $\mathrm{x}$," and 1.5 was the factor used to include possible variations that were due to lithological variations (Mohiuddin et al. 2010). Samples were considered unpolluted ( $\left.\mathrm{I}_{\text {geo }} \leq 0\right)$, unpolluted to moderately polluted $\left(0 \leq \mathrm{I}_{\text {geo }} \leq 1\right)$, moderately polluted $\left(1 \leq \mathrm{I}_{\text {geo }} \leq 2\right)$, moderate to strongly polluted $\left(2 \leq \mathrm{I}_{\text {geo }} \leq 3\right)$, strongly 


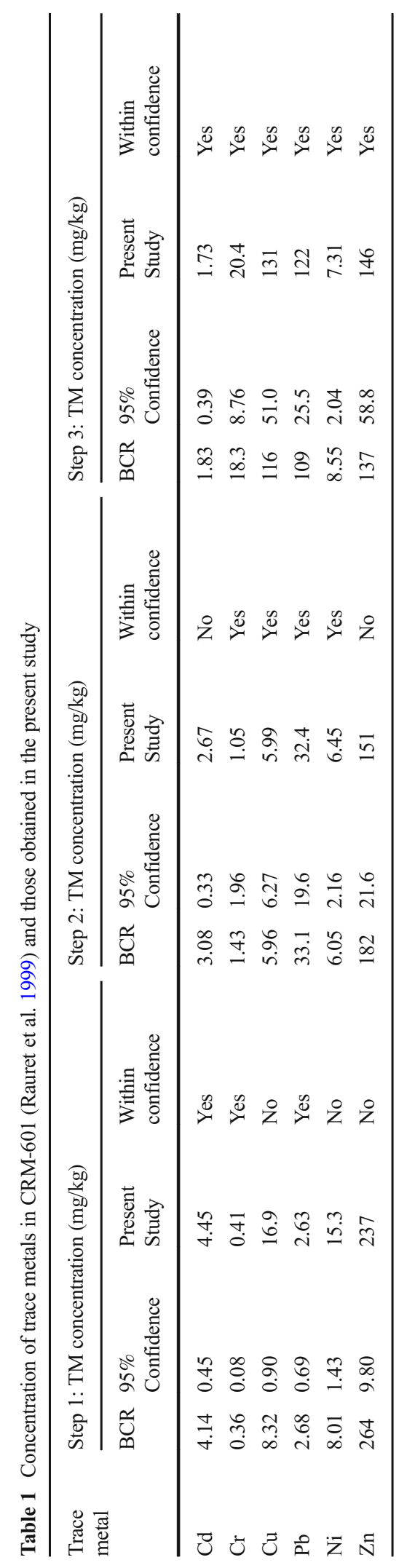

polluted $\left(3 \leq \mathrm{I}_{\text {geo }} \leq 4\right)$, strongly to extremely polluted $\left(4 \leq \mathrm{I}_{\text {geo }} \leq 5\right)$, and extremely polluted ( $\left.\mathrm{I}_{\text {geo }} \geq 5\right)$ according to Farkas et al. (2007).

Enrichment factor (EF) involved normalization of trace metal concentrations with respect to a reference metal such as $\mathrm{Zr}$, Al, or Fe. Both $\mathrm{Al}$ and Fe have relatively high natural concentrations, and are therefore not expected to be substantially enriched by anthropogenic activities in sediments. EF was calculated in the sediments according to Aprile and Bouvy (2008):

$\mathrm{EF}=\frac{\mathrm{C}_{\mathrm{xm}} / \mathrm{B}_{\mathrm{xm}}(\text { sediment })}{\mathrm{C}_{\mathrm{xm}} / \mathrm{B}_{\mathrm{xm}}(\text { background })}$,

where $\mathrm{C}_{\mathrm{xm}} / \mathrm{B}_{\mathrm{xm}}$ (sediment) was the metal concentration in relation to $\mathrm{Al}$ or $\mathrm{Fe}$ in sediment; $\mathrm{C}_{\mathrm{xm}} / \mathrm{B}_{\mathrm{xm}}$ (background) was the metal concentration in relation to $\mathrm{Al}$ or Fe in the crust (background). Based on EF, the degree of trace metal pollution was classified into seven classes namely: $\mathrm{EF}<1$ indicated no enrichment of metals; EF 1 to $<3$ indicated minor enrichment; EF 3 to $<5$ indicated moderate enrichment; EF 5 to $<10$ indicated moderate to severe enrichment; EF 10 to < 25 indicated severe enrichment; EF 25 to $<50$ indicated very severe enrichment, and EF 50 and above indicated extremely severe enrichment.

\section{Results}

Sediment chronology

Even though the ${ }^{210} \mathrm{~Pb}$ activity is relatively low in most of these cores, the data can be used to model age-depth relationship and estimate sedimentation rates. The ${ }^{210} \mathrm{~Pb}$ dates have been extrapolated to the upper $200 \mathrm{~cm}$ and the NR1, CR1, and SR1 sites are young dating back up to the 1970 s at $30 \mathrm{~cm}$. In contrast, sediments at NR3 and NR4 sites extend to the 1880 s at same depth. The measured ${ }^{210} \mathrm{~Pb}$ activity in the Rufiji delta mangrove sediments does not reach the background level at NR2, and hence the age could not be validated at this site. Sedimentation rate ranges from 0.4 at NR3 and NR4 sites to $1.75 \mathrm{~g} \mathrm{~cm}^{-2}$ year $^{-1}$ at SR1 site, respectively (Fig. 2 ). The sedimentation rates are $0.14 \mathrm{~cm}_{\text {year }}{ }^{-1}$ at NR1, $0.05 \mathrm{~cm} \mathrm{year}{ }^{-1}$ at NR3, $0.04 \mathrm{~cm} \mathrm{year}^{-1}$ at NR4, $0.10 \mathrm{~cm} \mathrm{year}^{-1}$ at CR1, and $0.28 \mathrm{~cm} \mathrm{year}^{-1}$ at SR1 sites (Fig. 2b). Sediment age in the deeper cores 
was extended to a maximum value of ca. 540 year by extrapolation.

\section{Grain size}

Figure 3 summarizes the results for grain size distribution in sediment cores from the Rufiji mangroves. The grain size distribution at sites NR1, NR2, and SR1 shows similar pattern. These sites have high clay content $(\sim 50 \%)$, followed by silt and sand. The percentage of fine grains (clay + silt) in the sediments is in the order $\mathrm{NR} 1 \geq \mathrm{SR} 1>\mathrm{NR} 2$. At NR3, clay particles dominate followed by silt and sand; the highest sand content (about 40 to $50 \%$ ) occurs at depth of $150-210 \mathrm{~cm}$. At this site, the sand content increases considerably compared to the other three sites. Similarly, site NR4 has higher sand than clay and silt content. Sediments at site CR1 have high clay (45\%) followed by silt and sand content. The overall order of decreasing fine-grain sediment content in the cores is NR1 $\geq \mathrm{SR} 1>\mathrm{NR} 2>\mathrm{CR} 1>$ NR3 $>$ NR4.

\section{Organic matter content}

Organic matter $(\mathrm{OM})$ content at the NR1 site ranges from $0.9 \%$ at $80 \mathrm{~cm}$ to $4.8 \%$ at $40 \mathrm{~cm}$ depth (Fig. 4). The NR2 site has similar trend for OM distribution as in $\mathrm{NR} 1$. OM at NR2 site ranges from $1.1 \%$ at $15 \mathrm{~cm}$ to $2.3 \%$ at $40 \mathrm{~cm}$. No definite trend is observed for these two sites. Instead, several outliers are observed. For NR3, NR4, CR1, and SR1 sites, OM content increases core upwards. NR3 site has OM ranging from $0.6 \%$ at $200 \mathrm{~cm}$ to $7.3 \%$ at $40 \mathrm{~cm}$. NR4 has OM content, ranging from $0.2 \%$ at $170 \mathrm{~cm}$ to $2.1 \%$ at $1.0 \mathrm{~cm}$. The $\mathrm{OM}$ content at CR1 site ranges from $0.4 \%$ at $200 \mathrm{~cm}$ to $5.7 \%$ at $5 \mathrm{~cm}$. In $\mathrm{SR} 1$ site, $\mathrm{OM}$ content ranges from 0.7 at $200 \mathrm{~cm}$ depth to $3.8 \%$ at $5 \mathrm{~cm}$ depth.

Distribution of trace metals in sediments

Trace metal concentrations in this study were compared to the certified trace metal values for the standard CRM601. The results observed are generally within range (except $\mathrm{Cu}$ and $\mathrm{Zn}$ ) confirming the extraction efficiency and reliability of our data (Table 1 ). The \% recovery of trace metals in the extractions is $>95 \%$. The distribution of specific trace metals $(\mathrm{Cd}, \mathrm{Cr}, \mathrm{Cu}, \mathrm{Pb}, \mathrm{Ni}$, and $\mathrm{Zn})$ in various fractions in the Rufiji sediments is presented in Figs. 5, 6, 7, 8, 9, and 10. Sites NR1 and NR2 have similar physical and chemical characteristics (except the dominant vegetation cover). Therefore, results from the NR1 site are presented in this study as a representative profile. Likewise, NR3 and NR4 sites have similar trends, and hence results from site NR3 are presented as a representative profile.

Cadmium (Cd) in the F1 fraction increases in concentration from surface to $100 \mathrm{~cm}$ depth at NR3, CR1, and SR1 sites (Fig. 5). The NR1 site has the highest $\mathrm{Cd}$ concentration at $160 \mathrm{~cm}$. Cd concentrations at NR1, NR3, CR1, and SR1 sites range up to $0.10 \mathrm{mg} \mathrm{kg}^{-1}$ in the F1 fraction. The highest concentration of Cd occurs between 40 and $120 \mathrm{~cm}$ at NR1, NR3, CR1, and SR1 sites. These depth intervals correspond to the period 1910-1980. In F2 fraction, the concentration of Cd ranges from 0.01 to $0.05 \mathrm{mg} \mathrm{kg}^{-1}$. There is minimal change in distribution of Cd with depth except at $40 \mathrm{~cm}$ (CR1 site) and $90 \mathrm{~cm}$ (NR1, NR3, and SR1 sites) depths that correspond to 1970 and 1920 when Cd concentrations increase sharply. In F3 fraction, $\mathrm{Cd}$ is $\leq 0.02 \mathrm{mg}$ $\mathrm{kg}^{-1}$, and concentration decreases slightly with age. The highest concentration of $\mathrm{Cd}$ occurs at $50 \mathrm{~cm}$ in $\mathrm{CR} 1,90 \mathrm{~cm}$ at NR3, $110 \mathrm{~cm}$ at SR 1 , and $180 \mathrm{~cm}$ at NR1 site. These depths correspond to the years 1970, 1930, 1910, and 1860, respectively, in these cores. Cadmium in F4 fraction at these sites ranges from 0.05 to $0.09 \mathrm{mg} /$ $\mathrm{kg}$ and indicates a gradual fluctuation in concentration. The overall trend for $\mathrm{Cd}$ in fractions 1 through 4 indicates a decreasing order $\mathrm{F} 1>\mathrm{F} 4>\mathrm{F} 2>\mathrm{F} 3$.

Chromium ranges from 0.09 to $0.22 \mathrm{mg} \mathrm{kg}^{-1}$ (Fig. 6). The concentration of $\mathrm{Cr}$ in $\mathrm{F} 1$ fraction is high towards the lower part or mid-section of the core (Fig. 6). Elevated concentration of Cr occurs at SR1, whereas at NR1, concentration decreases. At NR1 and CR1 sites, $\mathrm{Cr}$ increases in concentration towards the lower half of the core and this is followed by a steady decrease with depth. Cr at NR3 has a uniform distribution until it reaches $50 \mathrm{~cm}$, after which $\mathrm{Cr}$ increases in concentration. In F2 fraction, Cr shows high concentration in surface sediments followed by alternating decrease and/ increase of $\mathrm{Cr}$ at different depth intervals. Similarly, in the F3 and F4 fractions, $\mathrm{Cr}$ has the same trend and decreases with depth. The overall trend for $\mathrm{Cr}$ in fractions 1 through 4 indicates a decreasing order F4 $>$ F3 $>$ F2 $>$ F1.

Copper ranges from 0.01 to $15.1 \mathrm{mg} \mathrm{kg}^{-1}$ in the Rufiji sediments (Fig. 7). The concentration is low at NR3 compared to the other sites. The variation of $\mathrm{Cu}$ in $\mathrm{F} 1$ fraction increases from the top to about $100 \mathrm{~cm}$ at all 


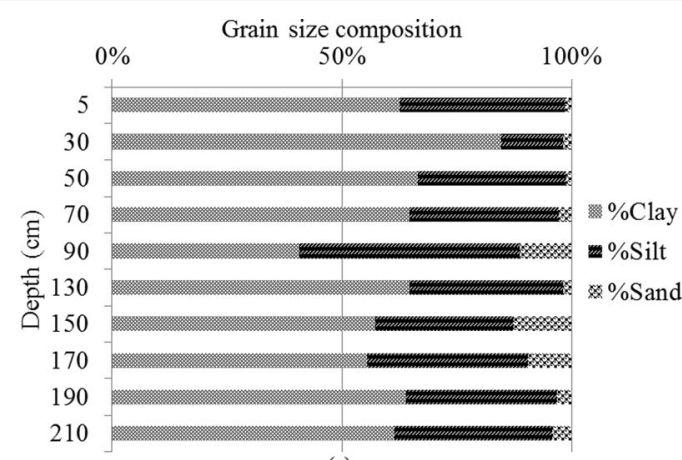

(a)

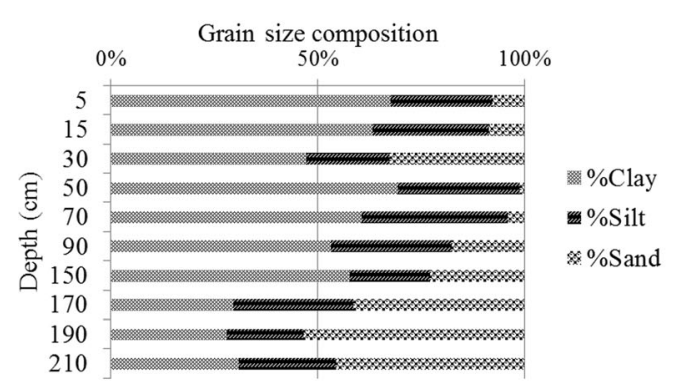

(c)

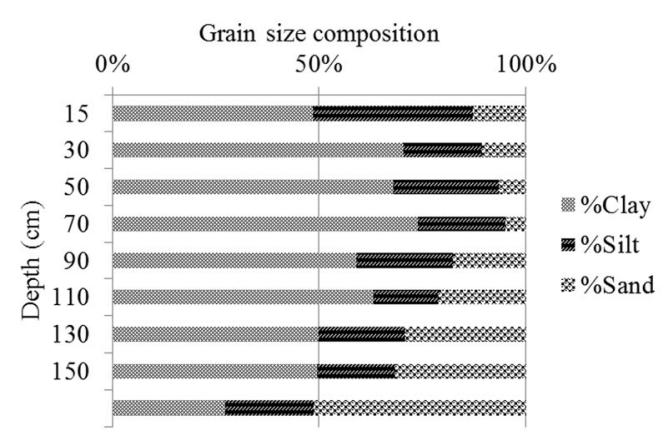

(e)

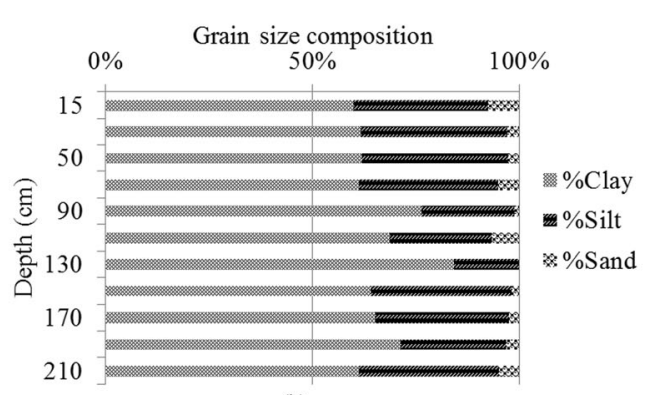

(b)

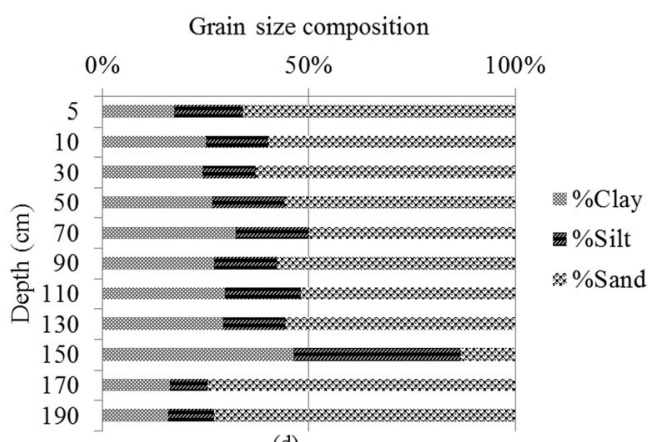

(d)

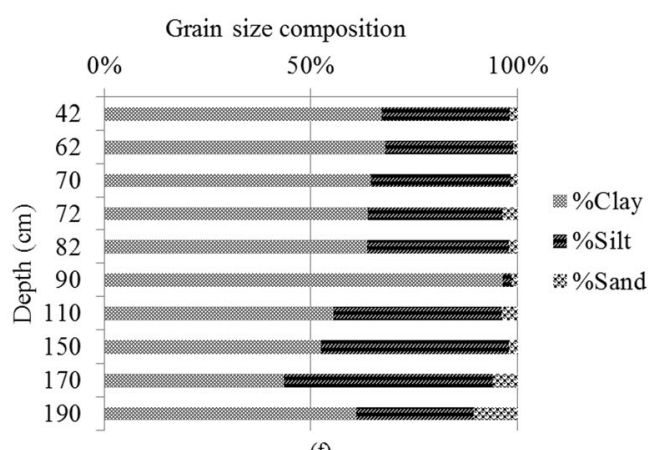

(f)

Fig. 3 The distribution of clay, silt, and sand at (a) NR1, (b) NR2, (c) NR3, (d) NR4, (e) CR1, and (f) SR1 sites in the Rufiji delta mangrove sediments

sites followed by a gradual decrease in its concentration. In F2 fraction, between the different sites, NR1 has the highest concentration that increases around 1960 at all sites. In F3 fraction, $\mathrm{Cu}$ gradually increases in concentration just around the mid-section before it decreases. In F4 fraction, $\mathrm{Cu}$ is more enriched near the top and surface sediments; $\mathrm{Cu}$ decreases with depth at different sites except at NR1.

Lead in the Rufiji sediments ranges from 11.5 to $17.0 \mathrm{mg} \mathrm{kg}^{-1}$ (Fig. 8). The concentration of $\mathrm{Pb}$ in $\mathrm{F} 1$ fraction slightly increases with depth, and the highest concentration at these sites occur around 40,80, and
$100 \mathrm{~cm}$, respectively (Fig. 8). There is a gradual decrease in $\mathrm{Pb}$ with depth at all sites, but a few outliers exist. In the F2 fraction, at NR1 and CR1 sites, the highest concentration of $\mathrm{Pb}$ occurs at $40 \mathrm{~cm}$. The NR3 and SR1 sites have the highest concentration at 60 and $90 \mathrm{~cm}$, respectively. In $\mathrm{F} 3$ fraction, $\mathrm{Pb}$ is high in the upper half of the core, but gradually decreases with depth. In F4 fraction, $\mathrm{Pb}$ shows less variation with depth unlike the other fractions. The highest concentration for $\mathrm{Pb}$ in F4 fraction occurs at $160 \mathrm{~cm}$ for both NR1 and NR3 sites, $60 \mathrm{~cm}$ at CR1 site, and at $100 \mathrm{~cm}$ in SR1 site. The overall trend for $\mathrm{Pb}$ in fractions 1 through 4 


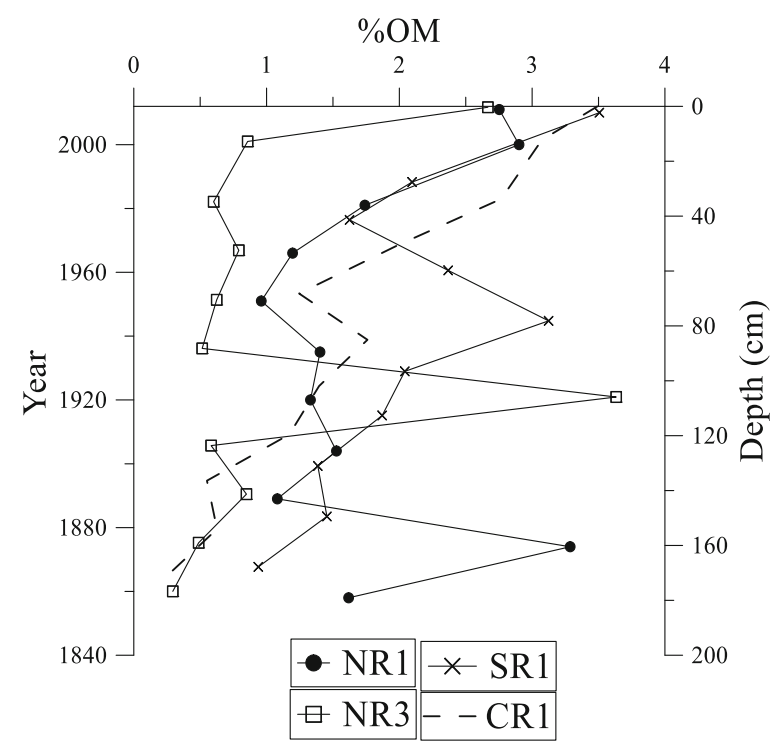

Fig. 4 Variation of organic matter content in the Rufiji delta mangrove sediments

indicates a decreasing order F2 $>$ F4 $>$ F3 $>$ F1. The average concentration of $\mathrm{Pb}$ at NR1, NR3, and CR1 sites is found to be statistically same, but different from SR1.

Nickel in the Rufiji delta sediments ranges from 0.20 to $23.8 \mathrm{mg} \mathrm{kg}^{-1}$ (Fig. 9). In F1 fraction, Ni significantly increases with depth from the surface to $100 \mathrm{~cm}$ followed by its decrease at NR3, CR1, and SR1 sites. Ni has high concentration up to $160 \mathrm{~cm}$ at NR1. In F2 fraction, the highest concentrations are at $160 \mathrm{~cm}$ in NR1. The NR3, CR1, and SR1 sites indicate a gradual increase in concentration in surface sediments down-core. The highest concentration in this fraction occurs at $20 \mathrm{~cm}$ (CR1), $60 \mathrm{~cm}$ (SR1), and $100 \mathrm{~cm}$ (NR3). Concentration of Ni is relatively high in the F4 fraction compared to F1, F2, and F3 fractions (Fig. 9).

$\mathrm{Zn}$ ranges from 0.01 to $47.5 \mathrm{mg} \mathrm{kg}^{-1}$ in these sediments (Fig. 10). Abundance of $\mathrm{Zn}$ at these sites is in the order NR1 > SR1 > CR1 > NR3 (Fig. 10). Distribution of Zn in F1 fraction increases a little from sediments near the top to $60 \mathrm{~cm}$ depth at CR1 and to $100 \mathrm{~cm}$ at NR3 and SR1 sites. There is no significant variation at NR1 site up to a depth of $140 \mathrm{~cm}$ and then $\mathrm{Zn}$ increases in concentration. Below $80-120 \mathrm{~cm}, \mathrm{Zn}$ shows a gradual decrease at all sites. In F2 fraction, the concentration of $\mathrm{Zn}$ at NR3 and CR1 sites increases with depth to its highest level at about 100 and $40 \mathrm{~cm}$, respectively. At NR1 and SR1 sites, the concentration of Zn slightly increases with depth. The F3 fraction has slightly higher $\mathrm{Zn}$ concentration with depth. The variation of $\mathrm{Zn}$ in $\mathrm{F} 4$ fraction indicates an overall decrease with depth. $\mathrm{Zn}$ is more enriched in the F4 fraction at NR1, NR3, CR1, and SR1 sites than in F1, F2, and F3 fractions.

Enrichment assessment of trace metals

Enrichment assessment in the Rufiji sediments was calculated with respect to several elements (besides the six elements discussed in the BCR protocol) to provide a more comprehensive picture of metal contamination at these sites. The EF and geoaccumulation index calculated for assessment of trace metal pollution at the different sites are presented in Tables 2 and 3, respectively.

\section{Discussion}

Deposition and physical characteristics

The Rufiji mangrove sediments show variability in sedimentation rate and chronology. Sites cores from NR1 and SR1 sites have the lowest sedimentation rate amongst the six sampled stations because these sites are inundated by tides, and they receive considerable amount of runoff water resulting in erosion and loss of sediments. Other factors contributing to the low sedimentation rates at these sites could be due to (1) physical and biological mixing at or near the sediment-water interface in surface sediments resulting in a flat ${ }^{210} \mathrm{~Pb}$ activity profile versus depth (Tylmann 2004), and (2) chemical diffusion or advection within the pore water at these sites (Gonçalves et al. 2012).

At NR3, clay particles dominate followed by silt and sand. Core NR3 has the highest sand content (40 to $50 \%$ ) at $150-210 \mathrm{~cm}$ depth. At this site, the sand content increases considerably compared to the other three sites. Similarly, site NR4 has higher (ca. 55\%) sand than clay and silt content. Sediments at CR1 site have higher (ca. $45 \%$ ) clay content than silt and sand. The overall order of decreasing fine-grain sediment content in the core is $\mathrm{NR} 1 \geq \mathrm{SR} 1>\mathrm{NR} 2>\mathrm{CR} 1>\mathrm{NR} 3>\mathrm{NR} 4$. A possible reason for such a trend is that NR1 and SR1 sites receive considerable amount of land-based run-off, which carries fine-grain sediments further downstream. In addition, location of these sampling sites with respect to the higher mangrove vegetation cover (density) has an influence on the grain size distribution pattern because it reduces the effect of erosion due to precipitation (Ewane and Heon 2016). 

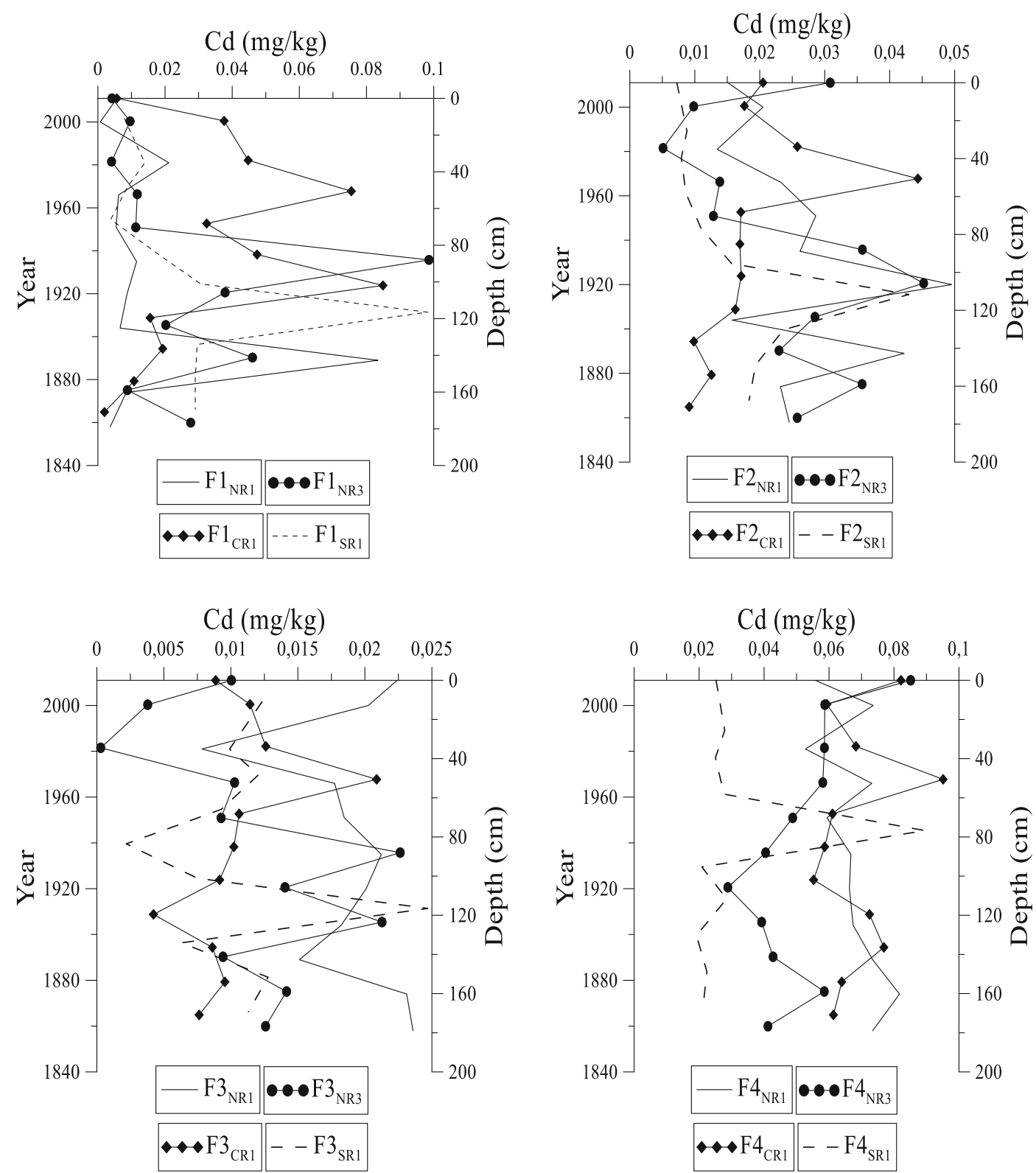

Fig. 5 Distribution of cadmium at NR1, NR3, CR1, and SR1 sites in fractions 1 to 4 in the Rufiji delta sediments

Chemical characteristics in mangrove sediments

Average OM content in Rufiji sediments has the highest (26.2\%) value at CR1 and the lowest (5.8\%) at NR4 site. In general, OM distribution in these sediments is closely associated with sediment texture and clay content. The presence of high OM content at CR1 and SR1 sites indicates input of $\mathrm{OM}$ from upstream run-off waters. These sites are affected by flooding during high tides, and water from the Indian Ocean enriched in marine
OM is deposited at sites CR1 and SR1. The NR3 site is currently a semi-desert and vegetation dieback and accumulation of plant matter in sediments results in high OM content at this site. Sites NR1, NR3, and NR2 are also influenced by anthropogenic activities such as logging, burning of charcoal, and farming, which contribute to the OM content at these sites. The sediment grain size rich in clay and silt fractions reflects that the large surface area of fine particles (sediment-specific surface area) results in greater sorption of OM to sediments. In 

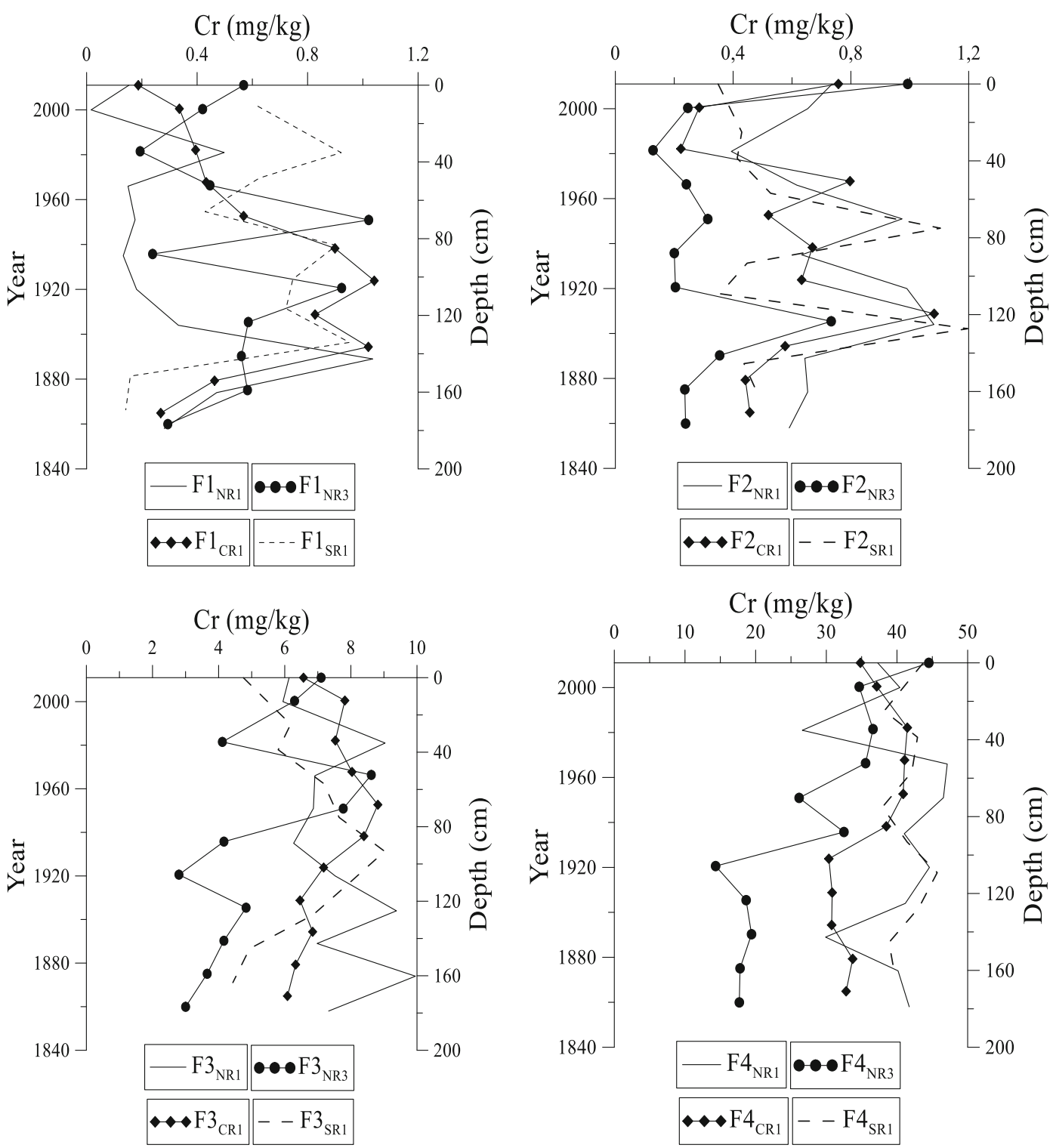

Fig. 6 Distribution of chromium at NR1, NR3, CR1, and SR1 sites in fractions 1 to 4 in the Rufiji delta mangrove sediments

addition, variation of OM content with depth is also affected by mineralization as part of the early diagenetic changes (Sanders et al. 2012), after the sediments are deposited.

The distribution of trace metals in different sediment fractions is based on the well-established BCR protocol. The protocol involves sequential chemical extraction to progressively leach out metals sorbed to the sediment matrix and assess their mobility. A one-way ANOVA tests shows that trace metal concentrations are significantly different between the stations $(p<0.005)$. The spatial variability could be due to the variation of mineralogical composition in sediments at the sampling sites or metals that are released from different sources. Fluvial influence on sediment transport plays an important role in trace metal distribution. As tidal currents increase, sediment particles are lifted into the water column and transported downstream towards the delta, particularly to those sites that are more exposed to sediment discharge from the Rufiji River. The distribution of trace metals at these sites is also influenced 

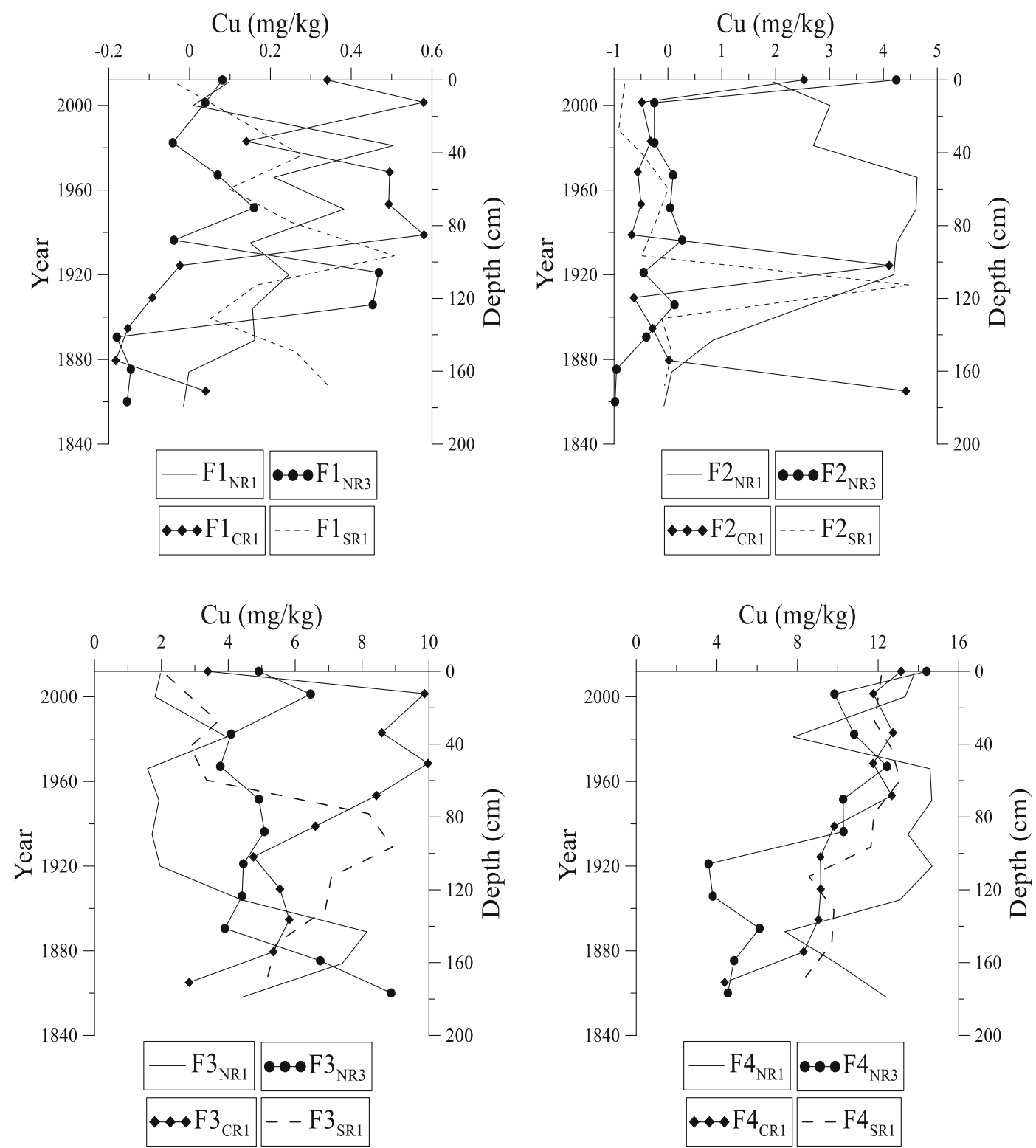

Fig. 7 Distribution of copper at NR1, NR3, CR1, and SR1 sites in fractions 1 to 4 in the Rufiji delta mangrove sediments

by $\mathrm{OM}$ content and Fe-Mn co-precipitation, and formation of insoluble precipitates that differ between the sites.

The relative contribution of $\mathrm{Cd}$ in $\mathrm{F} 1$ fraction in sediments is high compared to its distribution in other fractions. The dominance of lattice-bound $\mathrm{Cd}$ fraction (F4) over F2 and F3 fractions may be due to the facts that the Rufiji River erodes and carries Cdrich rock fragments and sediments from upstream that are later trapped in the mangroves. The overall Cd concentration is in the order $\mathrm{F} 1>\mathrm{F} 4>\mathrm{F} 2>\mathrm{F} 3$.
The sediment characteristics and fractionation in the Rufiji sediments suggests that $\mathrm{Cd}$ could be available for biological uptake at this site because it is mainly associated with the acid leachable (F1) fraction. Cadmium is slightly enriched in top sediments, which may be influenced by the particle size of sediments (Zhao et al. 2010) and OM content. The spatial distribution trend shows that $\mathrm{SR} 1>\mathrm{CR} 1>$ NR3 $>$ NR1 Cd concentrations. While the highest $\mathrm{Cd}$ concentration occurs in SR1, significant difference between the sites is absent. 

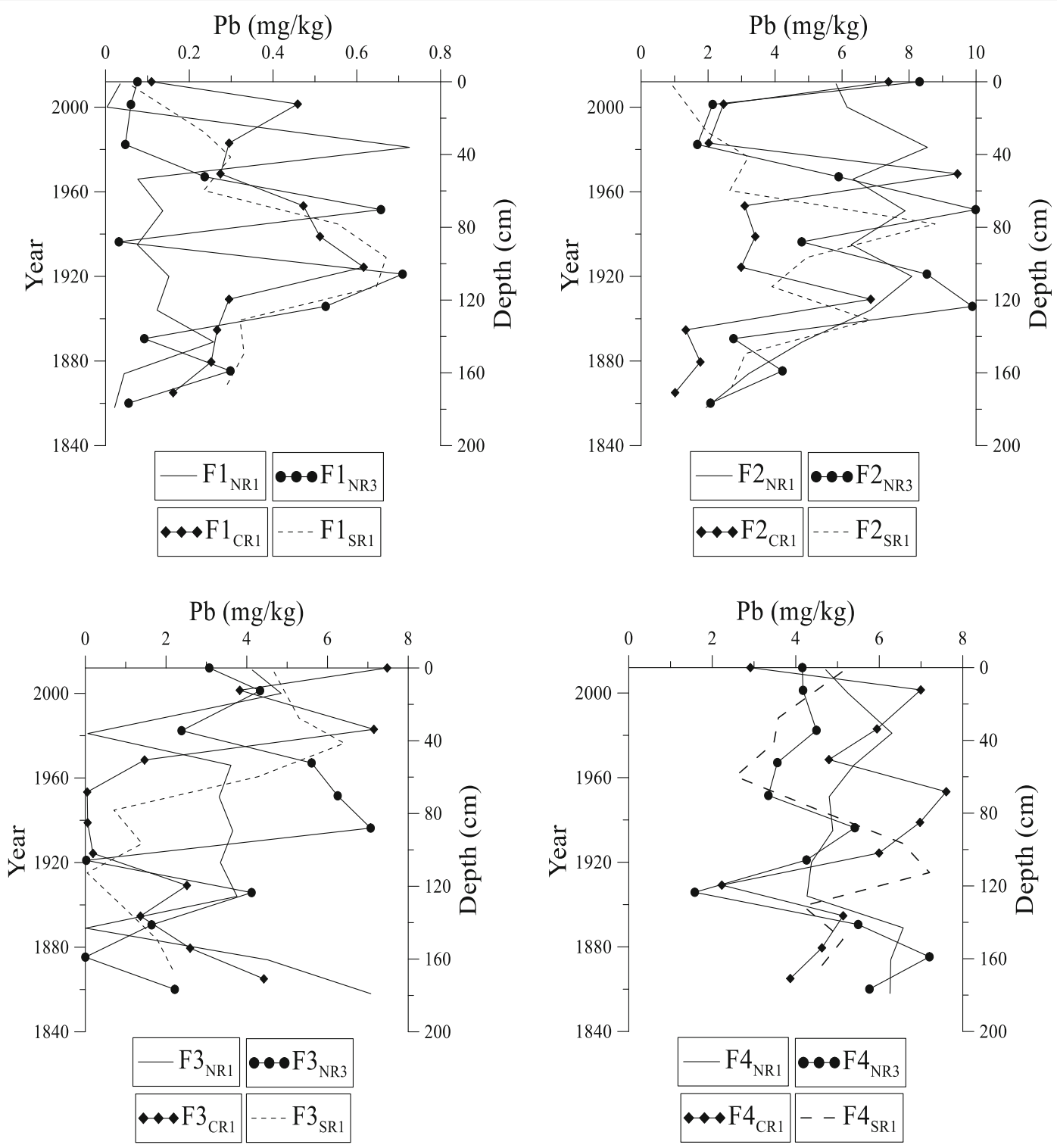

Fig. 8 Distribution of lead at NR1, NR3, CR1, and SR1 sites in Fractions 1 to 4 in the Rufiji delta mangrove sediments

Chromium is most enriched at the NR1 site. The presence of $\mathrm{Cr}$ in F1 and F2 fractions is most probably related to anthropogenic activities in upstream sections of the Rufiji River. In addition, $\mathrm{Cr}$ also occurs in the F3 fraction. Consistent with this, good correlation between the $\mathrm{F} 3$ fraction and organic carbon in surface sediments suggests scavenging of Cr by OM. However, F4 fraction constitutes $>95 \%$ of total $\mathrm{Cr}$ suggesting that $\mathrm{Cr}$ is primarily lattice-bound, and it is available for limited biological uptake. The low concentration of $\mathrm{Cr}$ in certain samples could be due to the high sand content at these depths. The overall trend for $\mathrm{Cr}$ in $\mathrm{F} 1$ through $\mathrm{F} 4$ fractions shows the order NR1 $>$ CR $1>$ SR $1>$ NR3 . The NR1 site receives considerable amount of run-off water from upstream sites carrying with it traces of metals that originate from chemical weathering, atmospheric deposition, and anthropogenic activities that increase the $\mathrm{Cr}$ levels in sediments.

Copper has the same trend as $\mathrm{Cd}$ in the Rufiji delta. However, in this study, $\mathrm{Cu}$ is more enriched in the $\mathrm{F} 4$ fraction than F3 fraction, particularly in surface sediments even though $\mathrm{Cu}$ has higher affinity for $\mathrm{OM}$, and readily forms complexes with humic substances (da Silva et al. 2014; Marchand et al. 2012). In general, 

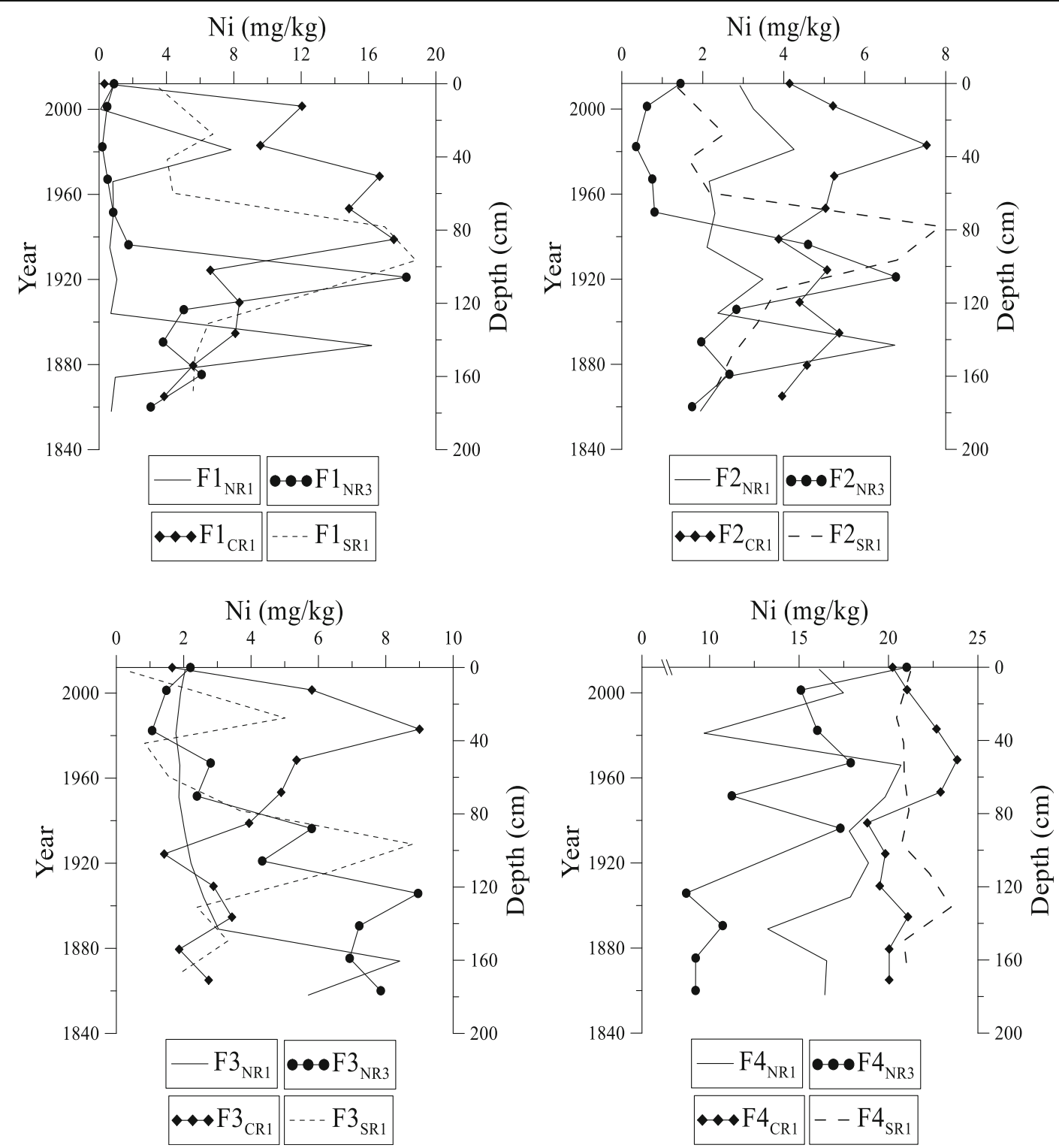

Fig. 9 Distribution of nickel at NR1, NR3, CR1, and SR1 sites in fractions 1 to 4 in the Rufiji delta mangrove sediments

$\mathrm{Cu}$ occurs in low concentration in the $\mathrm{F} 1$ and $\mathrm{F} 2$ fractions. Marchand et al. (2011) concluded that high metal concentration in the F3 fraction in mangrove sediments is due to the high OM content and anoxic conditions, which favor accumulation of metals in mangrove sediments. The overall spatial distribution for $\mathrm{Cu}$ in terms of abundance at different sites is in the order SR $1>$ NR1 $>$ CR1 $>$ NR3 sites.

Lead in these sediments reveals a moderately high concentration that is like other unpolluted places in East Africa (Christopher et al. 2014; Mwashote 2003; Ogoyi et al. 2011). Lead decreases with depth in the
F1 through F4 fraction, and the highest concentration at all sites occur between 40 and $120 \mathrm{~cm}$. Accumulation of $\mathrm{Pb}$ in surficial sediments is probably due to its relatively poor mobility and strong tendency to form metallo-organic complexes (Olade 1987). Consistent with this, spatial and temporal distribution of $\mathrm{Pb}$ is strongly associated with fine-grain sediments rich in OM content. Lead shows little association/affinity with Fe-Mn oxides in sediments. Distribution of $\mathrm{Pb}$ between the different sites decreases in the order SR $1>$ NR1 $>$ CR $1>$ NR3 suggesting that the SR1 site is more affected by anthropogenic activities. 

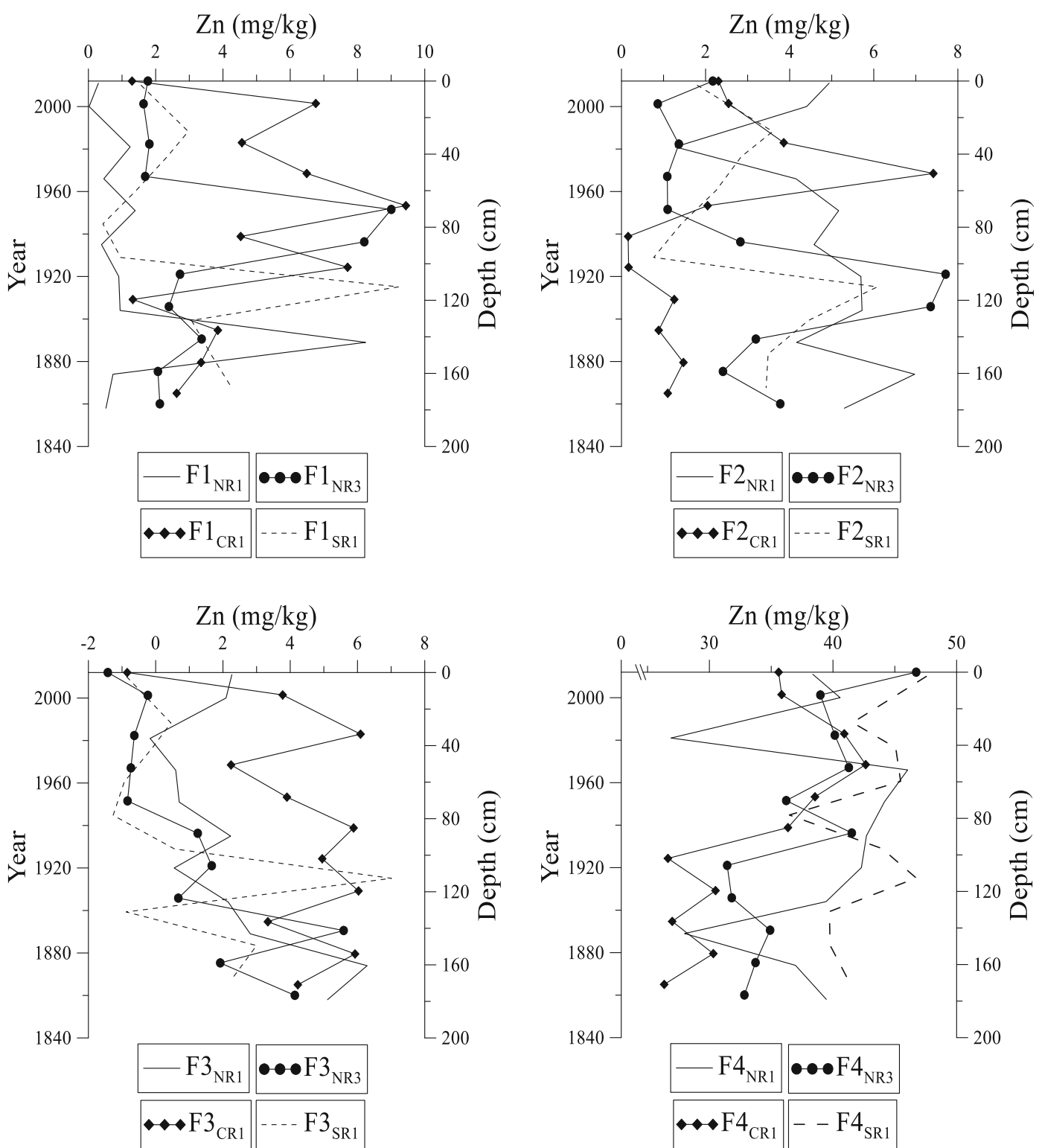

Fig. 10 Distribution of zinc at NR1, NR3, CR1, and SR1 sites in fractions 1 to 4 in the Rufiji delta mangrove sediments

Table 2 Enrichment factor of trace metals in the Rufiji mangrove sediments

\begin{tabular}{llllllllllll}
\hline & As & $\mathrm{Cd}$ & $\mathrm{Cr}$ & $\mathrm{Co}$ & $\mathrm{Cu}$ & $\mathrm{Fe}$ & $\mathrm{Pb}$ & $\mathrm{Mn}$ & $\mathrm{Ni}$ & $\mathrm{V}$ & $\mathrm{Zn}$ \\
\hline NR1 & 8.34 & 2.88 & 0.96 & 2.03 & 1.87 & 2.25 & 2.55 & 1.87 & 1.16 & 1.40 & 1.82 \\
NR2 & 7.22 & 0.75 & 1.07 & 1.54 & 2.21 & 2.2 & 2.98 & 2.97 & 1.09 & 1.52 & 1.77 \\
NR3 & 13.4 & 3.52 & 1.22 & 1.49 & 2.28 & 2.66 & 2.99 & 1.60 & 1.38 & 1.87 & 2.28 \\
NR4 & 7.22 & 3.85 & 1.32 & 1.81 & 2.50 & 1.89 & 3.12 & 2.58 & 1.15 & 1.79 & 2.44 \\
CR1 & 10.4 & 2.91 & 0.95 & 1.49 & 1.90 & 1.70 & 2.21 & 0.82 & 1.04 & 1.42 & 1.66 \\
SR1 & 7.89 & 4.22 & 1.19 & 2.13 & 2.78 & 2.06 & 2.72 & 1.26 & 1.22 & 1.95 & 2.18 \\
\hline
\end{tabular}


Table 3 Geoaccumulation index $\left(\mathrm{I}_{\text {geo }}\right)$ of trace metals in the Rufiji mangrove sediments

\begin{tabular}{llllllllllll}
\hline Site & $\mathrm{As}$ & $\mathrm{Cd}$ & $\mathrm{Cr}$ & $\mathrm{Co}$ & $\mathrm{Cu}$ & $\mathrm{Fe}$ & $\mathrm{Pb}$ & $\mathrm{Mn}$ & $\mathrm{Ni}$ & $\mathrm{V}$ & $\mathrm{Zn}$ \\
\hline NR1 & 0.34 & -0.12 & -0.59 & -0.27 & -0.3 & -0.22 & -0.17 & -0.3 & -0.51 & -0.43 & -0.32 \\
NR2 & 0.21 & -0.77 & -0.62 & -0.46 & -0.3 & -0.31 & -0.17 & -0.17 & -0.61 & -0.46 & -0.4 \\
NR3 & 0.30 & -0.28 & -0.74 & -0.65 & -0.47 & -0.4 & -0.35 & -0.62 & -0.69 & -0.55 & -0.47 \\
NR4 & -0.06 & -0.33 & -0.8 & -0.66 & -0.52 & -0.64 & -0.43 & -0.51 & -0.86 & -0.67 & -0.53 \\
CR1 & 0.36 & -0.19 & -0.68 & -0.48 & -0.37 & -0.42 & -0.31 & -0.74 & -0.64 & -0.5 & -0.43 \\
SR1 & 0.23 & -0.04 & -0.59 & -0.33 & -0.22 & -0.35 & -0.23 & -0.56 & -0.58 & -0.37 & -0.33 \\
\hline
\end{tabular}

Nickel is mostly ( $\geq 90 \%)$ associated with the F4 fraction. It is less than the typical concentration of $\mathrm{Ni}$ in sediments. For example, Chukwuemeka et al. (2014) and Stephen and Oladele (2012) reported that $\mathrm{Ni}$ in coastal sediments ranges from 1.00 to $80.0 \mathrm{mg} / \mathrm{kg}$. However, Cempel and Nikel (2006) reported that $\mathrm{Ni}$ content in sediments is variable and ranges from 3.00 to $1000 \mathrm{mg} \mathrm{kg}^{-1}$. The fact that $\geq 90 \%$ of Ni is associated with the F4 fraction, it suggests that $\mathrm{Ni}$ is perhaps not available for uptake by plants in the Rufiji sediments. On comparing the different sampling sites, it seems that the average concentration of $\mathrm{Ni}$ at $\mathrm{CR} 1$ shows significant differences with other sites $(p<0.05)$. This variability is mainly related to the OM content and grain size in sediments.

Zinc is enriched in surface sediments particularly in the F4 fraction. This suggests that deposition of $\mathrm{Zn}$ in sediments due to anthropogenic activities in the delta is minimal. CR1 has the highest $\mathrm{Zn}$ concentration, whereas the lowest concentration occurs in SR1. The spatial variation in $\mathrm{Zn}$ is probably due to dissolution of $\mathrm{Zn}$ derived from ocean that is carried by tides. Other than this, there is no significant statistical difference between the sites.

Enrichment assessment of trace metals in the Rufiji delta mangrove sediments

The EF for As shows moderate to high enrichment in Rufiji sediments at the NR1, NR2, NR4, and SR1 sites (Table 2). The EF for $\mathrm{Cd}$ in sediments ranges from 0.75 to 4.2 . At NR2, the EF value is below unity suggesting background concentration for $\mathrm{Cd}$ in these sediments. Cadmium is slightly enriched at the NR1 and CR1 sites (i.e., 2.88 and 2.91, respectively). At NR3, NR4, and SR1 sites, the EF values suggest moderate enrichment of $\mathrm{Cd}$. The $\mathrm{EF}$ values for $\mathrm{Cr}$ ranges from 0.95 to 1.32 suggesting lack of enrichment in NR1 and CR1 and minor enrichment at sites NR2, NR3, NR4, and SR1. In case of elements Co, $\mathrm{Cu}, \mathrm{Fe}, \mathrm{Ni}, \mathrm{V}$, and $\mathrm{Zn}$, the $\mathrm{EF}$ ranges from 1 to $<3$. This suggests low enrichment of these metals in the Rufiji sediments. Lead is moderately enriched at NR4, and slightly enriched at the sites NR1, NR2, NR3, CR1, and SR1. Similarly, enrichemnt of Mn in $\mathrm{CR} 1$ core is low, but it is more abundant at the other sites.

The $\mathrm{I}_{\text {geo }}$ value for As ranges from 0 to 1 suggesting that mangrove sediments are uncontaminated to moderately contaminated (except sediments from NR4 which has $\mathrm{I}_{\text {geo }}$ value $<0$ ). However, the results indicate that sediments are not contaminated in terms of $\mathrm{Cd}, \mathrm{Cr}, \mathrm{Co}$, $\mathrm{Cu}, \mathrm{Fe}, \mathrm{Pb}, \mathrm{Mn}, \mathrm{Ni}, \mathrm{V}$, and $\mathrm{Zn}$ since the $\mathrm{I}_{\text {geo }}$ values are negative (Table 3 ).

\section{Conclusions}

Trace metals in Rufiji sediments mainly occur in the residual phase (F4 fraction) at all sites. This suggests that these trace metals are of natural origin most likely arising from weathering of parent rocks in the catchment. The trends imply there is limited anthropogenic input that is further supported by the lack of high/ enriched concentrations in recently deposited sediments from upstream sections. The metal concentrations are high at sites which have high OM content and fine-grain size. The EF and $I_{\text {geo }}$ values for As are elevated in sediments from the Rufiji mangroves. The source for As enrichment at these sites is unclear. We recommend further studies in the Rufiji sediments with respect to $\mathrm{pH}$ and salinity differences that might affect their distribution locally. 
Acknowledgements We are grateful to the manager of the Rufiji mangrove forest for permission to conduct the sampling in Rufiji Delta. We wish to thank Ulomi Shadrack for his invaluable help during sampling and Harry Mallya who helped with sampling logistics. We thank Lena Lundman and Susanne Karlsson for their help in the laboratory. Finally, we thank the reviewers for their helpful suggestions.

Funding information We acknowledge the Swedish Research Link project-Africa (Grant 348-211-7408) for funding this study. This work was also partly supported by the Western Indian Ocean Marine Science Association (WIOMSA) and MARG 2 financial support to Andrew, Minu.

Open Access This article is distributed under the terms of the Creative Commons Attribution 4.0 International License (http:// creativecommons.org/licenses/by/4.0/), which permits unrestricted use, distribution, and reproduction in any medium, provided you give appropriate credit to the original author(s) and the source, provide a link to the Creative Commons license, and indicate if changes were made.

\section{References}

Abrahim, G. M. S., \& Parker, R. J. (2008). Assessment of heavy metal enrichment factors and the degree of contamination in marine sediments from Tamaki Estuary. Auckland. New Zealand. Journal Environmental Monitoring and Assessment, 136, 227-238.

Aderinola, J. O., Clarke, O. E., Olarinmoye, M. O., Kusemiju, V., \& Anatekhai, A. M. (2009). Heavy metals in surface water, sediments, fish and periwinkles of Lagos Lagoon. AmericanEurasian Journal of Agricultural and Environmental Science, 5, 609-617.

Appleby, P. G., \& Oldfield, F. (1983). The assessment of ${ }^{210} \mathrm{~Pb}$ data from sites with varying sediment accumulation rates. Hydrobiologia, 103, 29-35.

Aprile, F. M., \& Bouvy, M. (2008). Distribution and enrichment of heavy metals in sediments at the Tapacurá river basin, Northeastern Brazil. Brazilian Journal of Aquatic Science and Technology, 12, 1-8.

Borgese, L., Federici, S., Zacco, A., Gianoncelli, A., Rizzo, L., Smith, D. R., Donna, F., Lucchini, R., Depero, L. E., \& Bontempi, E. (2013). Metal fractionation in soils and assessment of environmental contamination in the Vallecamonica, Italy. Environmental Science Pollution Research International, 20(7), 5067-5075.

Byers, B., Aloyce, Z., Munishi, P., \& Rhoades, C. (2012). Tanzania environmental threats and opportunities assessment. USAID-Tanzania Report, $145 \mathrm{pp}$.

Cempel, M., \& Nikel, G. (2006). Nickel: a review of its sources and environmental toxicology. Polish Journal of Environmental Studies, 15, 375-382.

Centeri, C., Jakab, G., Szabó, S., Farsang, A., Barta, K., Szalai, Z., \& Bíró, Z. (2015). Comparison of particle-size analyzing laboratory methods. Environmental Engineering and Management Journal, 14(5), 1125-1135.
Christopher, M., Paul, O., \& Hamadi, B. (2014). Metal pollutants distribution within Lake Victoria basin and their influence on the native and transient microbial flora. Journal of Agricultural and Biological Science, 9, 127-133.

Chukwuemeka, A., Udo, G. J., \& Nwadinigwe, A. O. (2014). Seasonal variations of heavy metal concentrations in sediment samples around major tributaries in Ibeno Coastal Area, Niger Delta, Nigeria Nwadinigwe. International Journal of Scientific \& Technology Research, 3, 154-265.

da Silva, G. S., de Nascimento, A. S., de Sousa, E. R., Marques, E. P., Marques, A. L. B., Corrêa, L. B., \& Silva, G. S. (2014). Distribution and fractionation of metals in mangrove sediment from the Tibiri River Estuary on Maranhão Island. Revista Virtual de Química, 6, 323-336.

Ewane, E. B., \& Heon, H. L. (2016). Effects of vegetation cover on sediment particle size distribution and transport processes in natural rainfall conditions on post-fire hillslope plots in South Korea. Soil Research, 54, 937. https://doi.org/10.1071 /SR16117.

Farkas, A., Erratico, C., \& Vigano, L. (2007). Assessment of the environmental significance of heavy metal pollution in surficial sediments of the River Po. Chemosphere, 68, 761-768.

Fuller, C. C., van Geen, A., Baskaran, M., \& Anima, R. (1999). Sediment chronology in San Francisco Bay, California, defined by ${ }^{210} \mathrm{~Pb},{ }^{234} \mathrm{Th},{ }^{137} \mathrm{Cs}$, and ${ }^{239,240} \mathrm{Pu}$. Marine Chemistry, 64, 7-27.

Givelet, N., Roux, G. L., Cheburkin, A., Chen, B., Frank, J., Goodsite, M. E., Kempter, H., Krachler, M., Noernberg, T., Rausch, N., Rheinberger, S., Barraclough, F. R., Sapkota, A., Scholz, C., \& Shotyk, W. (2004). Suggested protocol for collecting, handling and preparing peat cores and peat samples for physical, chemical, mineralogical and isotopic analyses. Journal of Environmental Monitoring, 6, 481-492.

Gonçalves, W. F. O., Luiz-Silva, W., Machado, W., Nizoli, E. C., \& Santelli, R. E. (2012). Geochemistry of intertidal sediment pore waters from the industrialized Santos-Cubatão Estuarine System, SE Brazil. Anais da Academia Brasileira de Ciências, 84, 427-441.

Heiri, O., Lotter, A. F., \& Lemcke, G. (2001). Loss on ignition as a method for estimating organic and carbonate content in sediments: reproducibility and comparability of results. Journal of Paleolimnology, 25, 101-110.

Kilimwiko, L. (1997) Tanzania row over prawn plant in forests. Electronic Mail \& Guardian 1997; July 15.

Krishnaswamy, S., Lal, D., Martin, J. M., \& Meybeck, M. (1971). Geochronology of lake sediments. Earth Planetary Science Letters, 11, 407-414.

Marchand, C., Allenbach, M., \& Lallier-Verges, E. (2011). Relationships between heavy metals distribution and organic cycling in mangrove sediments (Conception Bay, New Caledonia). Geoderma, 160, 444-456.

Marchand, C., Fernandez, J. M., Moreton, B., Landi, L., LallierVergès, E., \& Baltzer, F. (2012). The partitioning of transitional metals ( $\mathrm{Fe}, \mathrm{Mn}, \mathrm{Ni}, \mathrm{Cr}$ ) in mangrove sediments downstream of a fertilized ultramafic watershed (New Caledonia). Chemical Geology, 300, 70-80.

Mohiuddin, M. K., Zakir, M. H., Otomo, K., Sharmin, S., \& Shikazono, N. (2010). Geochemical distribution of trace metal pollutants in water and sediments of downstream of an urban river. International Journal of Environmental Science \& Technology, 7, 17-28. 
Mremi, S. D., \& Machiwa, J. F. (2003). Heavy metal contamination of mangrove sediments and the associated biota in Dar es Salaam, Tanzania. Tanzania Journal of Science, 29, 61-76.

Mrutu, A., Nkotagu, H. H., \& Luilo, G. B. (2013). Spatial distribution of heavy metals in Msimbazi River mangrove sediments in Dar es Salaam coastal zone, Tanzania. International Journal of Environmental Science \& Technology, 3, 16411655.

Muller, G. (1969). Index of geoaccumulation in sediments of the Rhine river. Journal of Geology, 2, 108-118.

Mwashote, M. B. (2003). Levels of cadmium and lead in water, sediments and selected fish species in Mombasa, Kenya. Western Indian Ocean Journal of Marine Science, 2, 25-34.

Nemati, K., Bakar, N. K. A., Abas, M. R., \& Sobhanzadeh, E. (2011). Speciation of heavy metals by modified BCR sequential extraction procedure in different depths of sediments from Sungai Buloh, Selangor, Malaysia. Journal of Hazardous Materials, 192, 402-410.

Ogoyi, D. O., Mwita, C. J., Nguu, E. K., \& Shiundu, P. M. (2011). Determination of heavy metal content in water, sediment and microalgae from Lake Victoria, East Africa. The Open Environmental Engineering Journal, 4, 156-161.

Olade, A. M. (1987). Dispersion of cadmium, lead and zinc in soils and sediments of a humid tropical ecosystem in Nigeria (pp. 303-313). Hoboken: John Wiley \& Sons Ltd.

Paul, L. A., \& Oliver, H. (2005). Die-back of the mangrove Heritiera littoralis in Rufiji delta -TZ following El-Nino floods. Journal of Coastal Research, 42, 228-235.

Ranjan, R. K., Singh, G., Routh, J., \& Ramanathan, A. (2013). Trace metal fractionation in the Pichavaram mangrove-estuarine sediments in southeast India after the tsunami of 2004. Environmental Monitoring \& Assessment, 185, 8197-8213.

Rauret, G., López-Sánchez, J. F., Sahuquillo, A., Rubio, R., Davidson, C., Ure, A., \& Quevauvillier, P. H. (1999). Improvement of the BCR three step sequential extraction procedure prior to the certification of new sediment and soil reference materials. Journal of Environmental Monitoring, 1, $57-61$.

Rudnick, R. L., \& Gao, S. (2003). Composition of the continental crust. Treatise Geochem, 3, 1-64.

Rumisha, C., Elskens, M., Leermakers, M., \& Kochzius, M. (2012). Trace metal pollution and its influence on the community structure of soft bottom molluscs in intertidal areas of the Dar es Salaam coast, Tanzania. Marine Pollution Bulletin, 64, 521-531.

Sanders, C. J., Smoak, J. M., Waters, M. N., Sanders, L. M., Brandini, N., \& Patchineelam, S. R. (2012). Organic matter content and particle size modifications in mangrove sediments as responses to sea level rise. Marine Environmental Research, 77, 150-155.

Semesi, A.K. (2002). Mangrove management plan for mangrove ecosystem of mainland tanzania Vol 7, Part II, Block 7 mangrove management plan of Rufiji delta, Ministry of Tourism.

SIS. (1993). Swedish Standard Method SS 028150. Vattenundersökningar - Bestämning av metaller med atom absorptions spektrometri i flamma-Allmänna principer och regler (translated title-Water analyses-Metal analyses by flame atomic absorption spectroscopy-Principles and methods).

Stephen, O. O., \& Oladele, O. (2012). Distribution and temporal variation of selected heavy metals in sediment of River Osara mainstream drainage in North Central Nigeria. African Journal of Pure and Applied Chemistry, 6, 188-194.

Tafe, D. J. (1990). Zooplankton and salinity in the Rufiji River delta, Tanzania. Hydrobiologia, 208, 123-130.

Taylor, S. R., \& McLennan, S. M. (1995). The geochemical evolution of the continental crust. Reviews of Geophysics, 33, 241-265.

Taylor, M., Ravilious, C., \& Green, E.P. (2003). Mangroves of East Africa. UNEP-World Conservation Monitoring Centre, Biodiversity Series No. 13, 25 pp.

Tylmann, W. (2004). Estimating recent sedimentation rates using ${ }^{210} \mathrm{~Pb}$ on the example of morphologically complex lake (Upper Lake Raduñskie, N Poland). Geochronometria, 23, 21-26.

United Nations Environment Programme. (2001). Eastern Africa atlas of coastal resources: Tanzania. Nairobi: United Nations Environment Programme 117 pp.

United States Environmental Protection Agency. (2010). National coastal condition assessment laboratory methods manual. EPA No. In 841-R-09-002.

Zhao, H., Li, X., Wang, X., \& Tian, D. (2010). Grain size distribution of road-deposited sediment and its contribution to heavy metal pollution in urban runoff in Beijing, China. Journal of Hazardous Materials, 183, 203-210. 